\title{
Use of adhesion counts to help predict symptomatic infection and the ability of fluoroquinolones to penetrate bacterial biofilms on the bladder cells of spinal cord injured patients
}

\author{
G Reid, ${ }^{1,2}$ L Dafoe, ${ }^{1}$ G Delaney, ${ }^{3}$ M Lacerte, ${ }^{3}$ M. Valvano, ${ }^{1}$ K C Hayes ${ }^{3}$ \\ ${ }^{1}$ Department of Microbiology and Immunology, University of Western Ontario, London, \\ Canada; ${ }^{2}$ Division of Urology, University of Toronto; ${ }^{3}$ Department of Physical Medicine \\ and Rehabilitation, Parkwood Hospital, London, Canada.
}

\begin{abstract}
There were three objectives to the present study: (1) compare the bladder infection rate and extent of biofilm formation for seven untreated spinal cord injured (SCI) patients and seven given prophylactic co-trimoxazole, (2) identify a level of bacterial adhesion to bladder cells which could be used to help predict symptomatic infection, and (3) determine from in vivo and in vitro studies whether fluoroquinolones were effective at penetrating bacterial biofilms. The results showed that the infection rate had not changed with the introduction of prophylaxis. However, the uropathogenic population had altered subsequent to the introduction of prophylaxis with $E$. coli being replaced by $E$. faecalis as the most common cause of infection. In $63 \%$ of the specimens from asymptomatic patients, the bacterial counts per cell were $<20$, while $81 \%$ of specimens from patients with at least one sign and one symptom of urinary tract infection (UTI) had $>20$ adherent bacteria per bladder cell. Therefore, it is proposed that counts of $>20$ bacteria adherent to sediment transitional epithelial bladder cells may be predictive of symptomatic UTI. Clinical data showed that fluoroquinolone therapy reduced the adhesion counts to $<20$ per cell in $63 \%$ of cases, while trimethoprim-sulfamethoxazole only did so in $44 \%$. Further in vitro testing showed that ciprofloxacin $(0.1,0.5$ and $1.0 \mu \mathrm{g} / \mathrm{ml})$ partially or completely eradicated adherent biofilms from $92 \%$ of spinal cord injured patients' bladder cells, while ofloxacin did so in $71 \%$ cases and norfloxacin in $56 \%$. These findings have important implications for the detection and treatment of bacteriuria in spinal cord injured patients.
\end{abstract}

Keywords: bladder infections; bacterial adhesion; fluoroquinolone treatment; spinal cord injury patients.

\section{Introduction}

Symptomatic urinary tract infection (UTI) still remains a potentially life-threatening disease in spinal cord injured (SCI) patients and those with neurogenic bladder disturbances. ${ }^{1}$ The issue of whether or not to treat UTI and asymptomatic bacteriuria (ABU) in these patients has recently been raised $^{2}$ and recommendation made that asymptomatic bacteriuria should not be treated.

Correspondence: Dr Gregor Reid, Research Services, SLB 328, University of Western Ontario, London, Ontario N6A 5B8, Canada.
However, this recommendation was made without the knowledge that adherent bacterial biofilms exist on bladder cells and devices whether or not antibiotics are administered ${ }^{3,4.5}$ and the presence of these biofilms correlates with a significant loss in bladder cell viability. ${ }^{4}$ The use of prophylaxis, primarily with cotrimoxazole, is considered an effective method to prevent full blown bladder infection in otherwise healthy premenopausal women. ${ }^{6}$ However, its role as a prophylactic agent in SCI patients is less clear. 
The present study was undertaken to address three questions: (1) Does prophylactic management with co-trimoxazole lower bladder infection rates and eradicate adherent biofilms in SCI patients? (2) Does the number of adherent bacteria indicate whether or not a symptomatic infection will arise? (3) Are fluoroquinolones effective at penetrating and eradicating adherent biofilms? The latter question arises from in vitro and in vivo observations that of the many antimicrobial agents used to prevent and treat biofilm related infections, only ciprofloxacin, a potent fluoroquinolone, has shown good activity to date $\mathrm{e}^{5,7,8}$ (Preston CAK et al, unpublished).

\section{Materials and methods}

\section{Patients}

Fourteen SCI patients, aged 20-66 years (three females, 11 males), undergoing a hospital rehabilitation program provided written consent to participate in the study, approved by Parkwood Hospital and the University of Western Ontario Health Review Board. In all cases, bladder management comprised intermittent catheterization.

Each patient provided urine samples for 8 weeks. The urine specimens were cultured using standard microbiology laboratory techniques, and sediment transitional cells were Gram stained and the number of adherent organisms enumerated on 50 cells. In addition, cells from each sample were sonicated to remove adherent bacteria, and these organisms were then inoculated onto blood and brain heart infusion agar plates to determine the numbers of viable bacteria which had been attached to the cells.

The patients were monitored for signs and symptoms of UTI, namely spasticity, fever, cloudy and foul odour urine. Seven patients did not receive prophylactic therapy and seven were given daily co-trimoxazole (160 mg trimethoprim, $800 \mathrm{mg}$ sulfamethoxazole). Symptomatic UTI was actively treated with an agent to which the infecting bacteria was sensitive: namely, ciprofloxacin (500 mg b.i.d.), norfloxacin (400 mg b.i.d.), amoxacillin
(500 mg q8h), ampicillin (250 mg q.i.d.), co-trimoxazole (160 mg trimethoprim, $800 \mathrm{mg}$ sulfamethoxazole b.i.d.), gentamycin $(100 \mathrm{mg} \mathrm{q} 8 \mathrm{~h})$ or nitrofurantoin $(50 \mathrm{mg}$ q.i.d.).

In vitro incubation of epithelial cells with antibiotics

In order to determine if fluoroquinolones were able to kill adherent bacteria on the patients' epithelial cells, three concentrations $(0.1,0.5,1.0 \mu \mathrm{g} / \mathrm{ml})$ of ciprofloxacin, ofloxacin and norfloxacin were incubated with $10^{5}$ cells in $1 \mathrm{ml}$ buffer for 24 hours at $37^{\circ} \mathrm{C}$. The cells were then sonicated to remove adherent bacteria, and these were then washed and quantitated by culture on agar. The percentage reduction compared to untreated controls was calculated.

\section{Scanning electron microscopy}

A previous study ${ }^{3}$ had illustrated the presence of biofilms on bladder cells of SCI patients. In the latest study, several samples were processed for scanning electron microscopy to confirm these findings. A photomicrograph is included in Figure 1, not only for this purpose but also to illustrate the

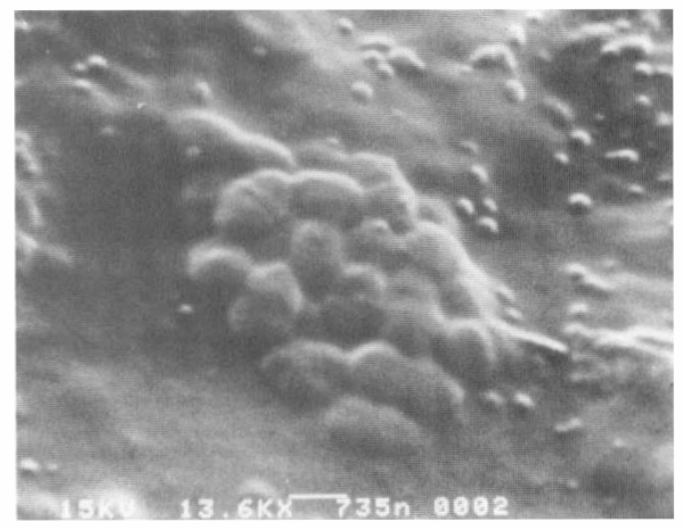

Figure 1 Scanning electron micrograph showing a microcolony of enterococci adherent to a transitional bladder cell of a spinal cord injured patient. The photograph appears slightly out of focus, but in fact this is due to the deposition of a conditioning film onto the surface of the cell and encasing the microorganisms. 
clumping of the organisms and the appearance of a conditioning film over the biofilm.

\section{Results}

The seven patients who had no antibiotic prophylaxis had an infection rate per sample of $68 \%$, which was not statistically higher than the $54 \%$ infection rate for the seven patients given prophylactic co-trimoxazole. However, as shown in Table I, the uropathogens isolated were quite different in each group, with $E$. coli being replaced by $E$. faecalis as the dominant pathogen upon use of co-trimoxazole.

An examination of the numbers of bacteria adherent per bladder cell showed a mean of $44 \pm$ SD 49 in 27 samples from the untreated patients, which was not statistically different from the mean of $39 \pm 42$ per cell from 26 samples from patients given co-trimoxazole prophylactically.

Sixteen specimens were able to be processed by sonication. There was no correlation between the number of adherent bacteria counted on cells by light microscopy and those found by sonication and quantitative culture (Fig 2). However, 11 of 16 $(69 \%)$ samples with mean adhesion counts $<20$ per cell had no bacteria recovered after sonication, whereas viable bacteria were recovered from all samples with means $>20$ per cell.

A combined analysis of bacterial adhesion counts from patients without signs or symptoms of UTI showed that in 19 of $30(63 \%)$

Table I Recovery of uropathogens in numbers $>10^{5}$ per $\mathrm{ml}$ urine from spinal cord injured patients untreated or given prophylactic co-trimoxazole

\begin{tabular}{lcc}
\hline & \multicolumn{2}{c}{$\%$ Recovery } \\
\cline { 2 - 3 } & $\begin{array}{c}\text { No } \\
\text { treatment }\end{array}$ & $\begin{array}{c}\text { Co- } \\
\text { trimoxazole }\end{array}$ \\
\hline E. coli & 35 & 0 \\
$P$. aeruginosa & 18 & 13 \\
K. pneumoniae & 18 & 0 \\
S. epidermidis & 18 & 0 \\
E. faecalis & 11 & 80 \\
Gram positive cocci & 0 & 7 \\
\hline
\end{tabular}

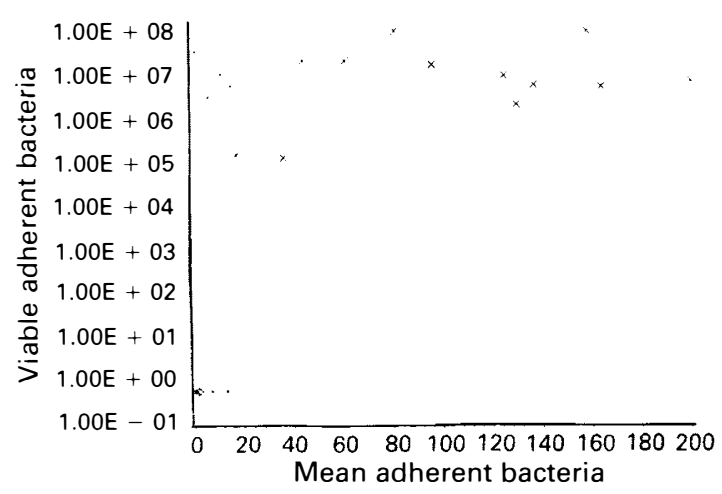

Figure 2 This graph presents the correlation between the number of bacteria visualized by Gram stain and light microscopy to be adherent to bladder cells from SCI patients, and the number of actual viable bacteria recovered from each sample of $10^{5}$ cells. A constant of 0.5 has been added to the count data.

cell specimens, the mean count was $<20$ per cell. In 26 of 32 specimens $(81 \%)$ where patients had at least one sign and one symptom of UTI, the adhesion counts were $>20$ per cell. Cloudy and foul odour urine per se would not be indicative of symptomatic infection and thus another symptom had to be recorded, such as spasticity, plus confirmation by culture of $>10^{5}$ organisms per ml urine.

A further examination of bladder cells from patients actively treated with ciprofloxacin and norfloxacin showed a mean of $<20$ bacteria per cell in five of eight samples $(63 \%)$, compared to 14 of $32(44 \%)$ when the patients were given co-trimoxazole.

All the isolated organisms tested for antibiotic penetration in vitro were sensitive to the fluoroquinolones, except one strain of E. faecalis. In vitro incubation of cells with adherent bacteria and the three fluoroquinolones showed that all three agents were equally effective at killing the adherent organisms (Table II). The increased eradication of bacteria at higher concentrations was not linear. The eradication of the adherent bacteria was partial or complete in $92 \%$ of the ciprofloxacin treated specimens, $71 \%$ of the ofloxacin (one sample was lost) and $56 \%$ of the norfloxacin specimens. 
Table II In vitro effect of fluoroquinolones on specimens of viable bacterial biofilms adherent to bladder cells from SCI patients, compared to untreated controls

\begin{tabular}{lccrrr}
\hline Antibiotic & $\begin{array}{c}\text { Concentration of antibiotic } \\
\text { used in vitro }\end{array}$ & $\begin{array}{c}\text { Mean \% reduction in } \\
\text { bacterial viability }\end{array}$ & $\begin{array}{c}\text { Biofilm eradication shown } \\
\text { as no. of samples }\end{array}$ \\
\cline { 4 - 6 } Ciprofloxacin & $0.1 \mu \mathrm{g} / \mathrm{ml}$ & 89 & 1 & 10 & 1 \\
& $0.5 \mu \mathrm{g} / \mathrm{ml}$ & 91 & 2 & 8 & 2 \\
Complete & Partial None \\
Ofloxacin & $1.0 \mu \mathrm{g} / \mathrm{ml}$ & 93 & 3 & 9 & 0 \\
& $0.1 \mu \mathrm{g} / \mathrm{ml}$ & 88 & 0 & 10 & 2 \\
Norfloxacin & $0.5 \mu \mathrm{g} / \mathrm{ml}$ & 88 & 1 & 5 & $5^{\mathrm{a}}$ \\
& $1.0 \mu \mathrm{g} / \mathrm{ml}$ & 90 & 2 & 7 & 3 \\
& $0.1 \mu \mathrm{g} / \mathrm{ml}$ & 86 & 0 & 7 & 5 \\
& $0.5 \mu \mathrm{g} / \mathrm{ml}$ & 86 & 0 & 5 & 7 \\
\hline
\end{tabular}

${ }^{\mathrm{a} O n e}$ sample was lost.

\section{Discussion}

The findings of the present study verified the presence of viable, and often dense, bacterial biofilms adherent to the transitional epithelial cells of SCI patients. The biofilms were often seen by microscopy to be embedded within a conditioning film (Fig 1). Although only 14 patients were examined, there was no evidence to indicate that the UTI rate had decreased with the use of prophylactic co-trimoxazole. A study of 81 patients is now underway to determine more conclusively whether prophylactic therapy altered the infection rate and to what extent it impacted upon uropathogen strain, patient wellbeing and cost. In the present study, there was strong evidence to indicate that $E$. faecalis had replaced $E$. coli as the major cause of UTI following the introduction of prophylaxis. A previous Japanese study of patients with complicated UTI (underlying neurogenic bladder dysfunction and cancer) has shown a high incidence of enterococcal infection and drug resistance to many antimicrobial agents, including co-trimoxazole $(57 \%) .{ }^{9}$ Of the few cases treated with ciprofloxacin, norfloxacin, enoxacin and ofloxacin, good eradication rates were found with few cases of recurrence. This compares favourably with the findings of the present study where in vitro fluoroquinolone concentrations were 100-1000-fold lower than those present in the bladder of patients treated with these antibiotics.

One of the major problems in the management of SCI patients is predicting when the asymptomatic bacteriuria will go on to cause symptomatic infection and morbidity. The data obtained in the present study indicated that signs and symptoms of UTI were associated with mean bacterial adhesion counts of over 20 organisms per cell. Clearly, these data alone are not sufficient to influence clinical decision making and larger numbers of SCI patients and other patient groups must be tested to confirm the observation. The key will be to produce a diagnostic assay which is sufficiently sensitive and specific to put these in vitro findings into practice. By providing a physician with information on the nature and extent of bladder cell colonization, it should be feasible to better decide if antibiotic therapy is required.

An examination of the bacterial adhesion counts showed that there was some correlation between the ability of more adhesive (and perhaps more virulent) uropathogens to cause symptomatic UTI, in agreement with in vitro results for $E$. coli. ${ }^{10}$ In cases where there was no correlation between adhesion per cell and numbers of bacteria recovered from sonicated cells (Fig 2), there could be several explanations. (1) A number of the adherent bacteria may have been killed by antibiotics, but still have remained attached. (2) The light microscopy 
technique may have underestimated the numbers of adherent bacteria, especially cocci which, as Figure 1 shows, can be present in small microcolonies.

The potential of fluoroquinolones, especially ciprofloxacin, to penetrate adherent biofilms appears to have some merit, based upon in vitro studies. ${ }^{7,8}$ In the present study, ciprofloxacin and norfloxacin therapy reduced the adhesion counts to $<20$ per cell in $63 \%$ of cases and co-trimoxazole only did so in $44 \%$. Admittedly, this difference could be due to relative activity of the antibiotics rather than ability to penetrate biofilms. However, further in vitro studies confirmed the potency of three fluoroquinolones at killing adherent bacteria on the epithelial cells, and showed that low doses had a partial effect. These findings do not necessarily mean that fluoroquinolones should be used prophylactically or as the drug of choice to treat UTI in SCI patients. Certainly, there are arguments for using less expensive products such as co-trimoxazole, which at our institution costs around 10 cents per tablet compared to having to use active therapy to clear an infection, for example using $400 \mathrm{mg}$ norfloxacin $\mathrm{q} 12 \mathrm{~h}$ at $\$ 2$ per tablet or $500 \mathrm{mg}$ q12 h ciprofloxacin at $\$ 2.60$ per tablet. However, unless an antibiotic is able to penetrate and/or eradicate bacterial biofilms, its effectiveness is questionable (except that it may prevent spread of planktonic E. Coli to the kidney) and its usage could result in the emergence of more problematic pathogens.

Clinical trials will be required to verify that ciprofloxacin and other fluoroquinolones can truly eradicate biofilms and provide a clinically significant endpoint. Further studies would also be useful with shorter courses (which have been effective in otherwise healthy adults) ${ }^{11}$ or even subminimum inhibitory concentrations of ciprofloxacin, to reduce adhesion and temporarily prevent recurrence of infection, without giving rise to a significant increase in the number of drug resistant uropathogens.

\section{Acknowledgements}

This work was supported by a grant from the Rick Hanson Man in Motion Foundation, and in part by Miles Canada. The technical support of Ms D Lam was appreciated and was supported by the Medical Research Council of Canada. We are grateful to Dr David Colby, University Hospital in London, for assisting with the laboratory microbiology, and to Ms D Reid for proofreading.

\section{References}

1 Stover SL, Lloyd LK, Waites KB, Jackson AB (1989) Urinary tract infection in spinal cord injury. Arch Phys Med Rehabil 70: 47-55.

2 National Institute of Disability and Rehabilitation Research Consensus Statement (1992) The prevention and management of urinary tract infections among people with spinal cord injuries. J Am Paraplegia Soc 15: $194-204$.

3 Reid G, Charbonneau-Smith R, Lam D et al (1992) Bacterial biofilm formation in the urinary bladder of spinal cord injured patients. Paraplegia 30: 711-717.

4 Reid G, Kang YS, Lacerte M et al (1993) Bacterial biofilm formation on the bladder epithelium of spinal cord injured patients. II. Toxic outcome on cell viability. Paraplegia 31: 494-499.

5 Reid G, Denstedt JD, Kang YS et al (1992) Bacterial adhesion and biofilm formation on ureteral stents in vitro and in vivo. J Urol 148: 1592-1594.

6 Nicolle LE, Harding GKM, Thomson M et al (1988) Efficacy of five years of continuous, low-dose trimethoprim-sulfamethoxazole prophylaxis for urinary tract infection. J Infect Dis 157: 1239-1242.

7 Reid G, Tieszer C, Foerch R et al (1993) Adsorption of ciprofloxacin to urinary catheters and effect on subsequent bacterial adhesion and survival. Colloids Surfaces B: Biointerfaces 1: 9-16.

8 Nikolov R, Khoury AE, Bruce AW, DiCosmo F (1993) Interaction of ciprofloxacin loaded liposomes with Pseudomonas aeruginosa cells. Cells Materials 3: 321-326.

9 Matsumoto T, Kumazawa J (1989) Significance of enterococci in chronic complicated urinary tract infection. In Kass EH, Svanborg Eden C, editors. Host-parasite Interactions in Urinary Tract Infections. University of Chicago Press, Chicago: 194-197.

10 Svanborg Eden C, Hanson LA, Jodal U et al (1976) Variable adherence to normal human urinary-tract epithelial cells of Escherichia coli strains associated with various forms of urinary-tract infection. Lancet 2: 490-492.

11 Pfau A, Sacks TG (1993) Single dose quinolone treatment in acute uncomplicated urinary tract infection in women. J Urol 149: 532-534. 